\title{
Fatty Acid-rich Trout Bone Soup Demonstrates Potential to Mask Bitterness of Food and Chinese Medicine
}

\author{
Ying Han ${ }^{1}$, Zhizhou Zhang ${ }^{1,2,3, *}$ \\ ${ }^{1}$ School of Chemistry and Chemical Engineering, Harbin Institute of Technology, Harbin 150001, China \\ ${ }^{2}$ School of Marine Science and Technology, Harbin Institute of Technology, Weihai 264209, China \\ ${ }^{3}$ Marine Antifouling Engineering Technology Center of Shandong Province, Weihai, 264209, China \\ *Corresponding author: zhangzzbiox@hitwh.edu.cn \\ Received January 06, 2018; Revised February 24, 2019; Accepted March 16, 2019
}

\begin{abstract}
Many Chinese medicine soups are very bitter and hard for children to drink. Some direct and simple bitter-masking approaches in daily food and Chinese medicine are always of great need. In this study, a rainbow trout bone soup-based efficient de-bittering method was discovered by serendipity when the authors tried to attenuate the bitterness of the bone soups made from cod and salmon. The bitterness of one of the bitterest daily food, bitter mellon, was completely removed by the trout bone extract. The bitterness of the soups of Coptis chinensis and kuh-seng, two of the extreme bitter Chinese medicine, were also eliminated with high efficiency. Bone soups made of cod and salmon didn't have de-bittering function. Fatty acids composition analysis was performed with the bone soups made from cod, salmon and trout, and the results clearly demonstrated that the trout soup has much higher concentrations of myristic acid, palmitic acid, stearic acid, cis-9-hexadecenoic acid, and cis-9-octadecenoic acid. The combination of the five pure fatty acids did display the capacity to almost remove the bitterness of all above tested soup materials, either food or Chinese medicine. But other combinations (less than five components) cannot achieve the same level of de-bittering effect.
\end{abstract}

Keywords: fatty acids, bitterness, masking, trout, bone soup

Cite This Article: Ying Han, and Zhizhou Zhang, "Fatty Acid-rich Trout Bone Soup Demonstrates Potential to Mask Bitterness of Food and Chinese Medicine." Journal of Food and Nutrition Research, vol. 7, no. 3 (2019): 224-230. doi: 10.12691/jfnr-7-3-7.

\section{Introduction}

In traditional Chinese medicine, most drug materials are characterized with four-Qi and five-taste, in which four-Qi means chill, hot, warm or cool, and five-taste means sour, sweet, bitter, spicy, or salty [1]. Japanese scientists often classify basic tastes in food or drugs as sweet, salty, sour, bitter, and umami [2]. In particular, bitter taste is generally unfavorable and tends to be aversive to most people. Bitter-tasting foods are hard to be accepted in a long term except some slightly bitter ones such as beer, wine and coffee. For pharmaceutical compounds with medical benefits, bitterness taste is frequently encountered for patients, and it often reduce compliance with a treatment regimen especially for children. Therefore, bitterness masking technology is considered important in both food processing and pharmaceutical manufacturing.

In the BitterDB database [3,4], most of listed about 700 bitter substances are small molecules of various chemical categories. One type of the common bitterness in fish is often derived from cholic acid or bitter amino acids (histidine, leucine, isoleucine, methionine, etc.). Fish tissue waste (skin, tail, bones, fishbone, fins, visceral, etc.) is often mixed with bile or bile acid and other bitter substances, resulting in a taste of obvious bitterness. In theory, it is possible to eliminate the cholic acid or bitter amino acids through specific biotransformation reactions. Many kinds of food will form a bitter taste after the hydrolysis, seriously affecting oral sensation. The bitterness of the hydrolates is partially due to the release of bitter peptides. At present, there are at least over one hundred known bitter peptides [5-14].

Decent progresses have been achieved in bitterness-masking technology development. Various protein hydrolysates with bitter tastes were found from 1950s [15]. Since then, researchers have proposed de-bittering methods such as activated-carbon adsorption, chloroform extraction, ethanol extraction, isoelectric point precipitation, hydrophobic interaction chromatography, and other bitter masking approaches [16-21]. Encapsulation or molecular binding plus other molecular levels of studies brought more specific approaches to mask bitterness. For example, coating and encapsulating are frequently used in the biomedical industry to mask the bitterness of drugs $[22,23]$. The formation of inclusion complexes between various target substances and cyclodextrin can be 
employed to mask bitterness [24]. Phosphatidic acid and its lipoprotein derivative have been reported to deter the bitterness of quinine [25]. Bitterness can also be masked by introducing antagonists of bitter taste receptors (T2Rs) into food or drug coatings [26]. Besides, amino acid derivatives as low-molecular-weight bitterness-masking compounds are worthy considering in some cases [27]. Zinc chemicals were also found to mask the bitterness of quinine, tetralone, and denatonium benzoate [28]. For both food processing and drug manufacturing, bitternessmasking compounds or approaches must be harmless and biocompatible, so identifying safe bitterness-masking agents originating from foods is a desirable objective. More bitterness masking techniques derived from natural food or herbs with low cost are highly expected.

In the beginning of this study, the authors tried to attenuate the bitterness of one local soup product made from cod and salmon bones by using a bitter peptide digestion approach. The origin of the product's heavy bitterness was not very clear because cod and salmon bone soups themselves are only slightly bitter. The authors guessed that the product's bitterness might come from some released bitter peptides from cod and salmon proteins (and proteins of other origins in the product). After a series of experiments, it was found that bitter peptide digestion approach was only able to partially eliminate the product's heavy bitterness (data not shown). However, we found, by serendipity, that the trout bone soup can completely eliminate the product's bitterness. Then we tested whether the trout bone soup could mask bitterness from different typical bitter food and Chinese medicine. Satisfactory de-bittering effects were steadily observed, and the main fatty acids components were analyzed and compared among cod, salmon and trout bone soups. Key de-bittering or bitterness-masking fatty acids components in the trout bone soup were proposed and confirmed by a series of experiments. This study revealed the potential for the trout bone soup to be a low-cost debittering reagent that may be widely implicated in food processing and Chinese medicine production.

\section{Materials and Methods}

\subsection{Bone Soups}

All kinds of fresh fish bone were provided by The YueYi Biotech Ltd, RiZhao, Shandong, China. Each fish bone still has some fish meat around it, with about $15-20 \% \mathrm{~W} / \mathrm{W}$ fish meat of the whole weight. Each bone was cut into pieces less than the size of $2 \mathrm{~cm} \times 5 \mathrm{~cm} \times 1 \mathrm{~cm}$. Cod (Gadus macrocephalus) fish bone was equally mixed with water $(\mathrm{W} / \mathrm{W})$, smashed with a laboratory stirrer (Insinkerator E200, JingDong,China) to get a cod bone suspension. The suspension was further equally mixed with water $(\mathrm{V} / \mathrm{V})$ and then heated to the boiling state for $20 \mathrm{~min}$ to get the cod bone soup. Trout (Oncorhynchus mykiss) and salmon (Oncorhynchus masou) bone soups were made in the same way.

\subsection{Plants Bitter Soup}

Coptis chinensis [29] and kuh-seng, two highly bitter types of Chinese medicine, were purchased in the
YanXiTang Pharmacy. Bitter melon (Momordica charantia) [30] was bought in Jiajiayue supermarket, Weihai, China. Each of the three above substances was cut into small pieces no larger than the size of $1 \mathrm{~cm} \times 0.5 \mathrm{~cm} \times 0.5 \mathrm{~cm}$. The initial concentration of Coptis chinensis soup, kuh-seng soup and bitter melon soup were $0.025 \mathrm{~g} / \mathrm{ml}, 0.025 \mathrm{~g} / \mathrm{ml}$ and $0.5 \mathrm{~g} / \mathrm{ml}$, respectively, heated to the boiling state for 20 min to get the soup, and the three above soups were diluted 50, 10 and 10 times respectively in the sensory evaluation tests.

\subsection{General Fat and Fatty Acids Analysis}

Cod, trout and salmon bone soups were freshly prepared, each with three replicates, and were immediately subjected to lipid extraction according to the protocol of GBT 5009.6-2003. Well suspended and homogenated fish bone samples $(50 \% \mathrm{~V} / \mathrm{V}$ for cod, trout and salmon) $10 \mathrm{ml}$ each were mixed with $20 \mathrm{~g}$ clean sea sand and dried upon the boiling water, then further dried at $105^{\circ} \mathrm{C}$ in an oven. The dried powder was further homogenated and put onto the folded filter-paper before loaded into Soxhlet's extractive tube. After extraction with ether for $10 \mathrm{hr}$, the general fat biomass was dried completely to weight the amount of free fat biomass.

An aliquot of the total lipid extract was transmethylated to produce fatty acid methyl esters according to the protocol of GB/T 17376-2008. Briefly, 250mg fat biomass in a $50 \mathrm{ml}$ flask was mixed with $7 \mathrm{ml}$ boron trifluoride $(15 \% \mathrm{~W} / \mathrm{V}$ in methanol). The flask was assembled with a condenser to boil the solution for $30 \mathrm{~min}$. Around $8 \mathrm{ml}$ isooctane was added into the boiling solution, then followed by $20 \mathrm{ml}$ saturated $\mathrm{NaCl}$ solution. Detach the flask and vortex vigorously for $15 \mathrm{~s}$. Keep adding saturated $\mathrm{NaCl}$ solution till the top of the flask. Wait $1 \mathrm{hr}$ for separation of solution layers. Take $1.5 \mathrm{ml}$ the upper isooctane supernatant and mix with some anhydrous sodium sulfate to get rid of residual water. Then the sample can be loaded for GC capillary analysis according to the protocol of GBT 17377-2008. The supernatant $(1 \mu \mathrm{L})$ was analyzed using GC-FID (Agilent 7890A) gas (Nitrogen) chromatography. The analytes were separated on an HP-88 fused silica capillary column $(100 \mathrm{~m} \times 0.25$ $\mathrm{mm}, 0.20 \mu \mathrm{m}$ film thickness, Agilent Technologies, Santa Clara, CA, USA). The split ratio was 100:1 with a $1.25 \mathrm{~mL} / \mathrm{min}$ flow rate. The injector and transfer line temperature were set at $250^{\circ} \mathrm{C}$ and $240^{\circ} \mathrm{C}$, respectively. The oven temperature followed a program of $100^{\circ} \mathrm{C}$ for initial $13 \mathrm{~min}$, a ramp of $10^{\circ} \mathrm{C} / \mathrm{min}$ to $180^{\circ} \mathrm{C}$, holding at $6 \mathrm{~min}$, another ramp of $1^{\circ} \mathrm{C} / \mathrm{min}$ to $200^{\circ} \mathrm{C}$ and holding at $20 \mathrm{~min}$; then the last ramp of $4^{\circ} \mathrm{C} / \mathrm{min}$ to $230^{\circ} \mathrm{C}$ and holding at $10.5 \mathrm{~min}$. The analytes were assigned by comparing retention times with authentic standards. The quantification was performed using calibration curves composed by plotting peak area ratios of the analyte to the internal standard against analyte concentrations. The general fat and fatty acids compositions were measured with the facilities in Merieux Nutrisciences, Sino Analytical (Qingdao) Ltd, China. Pure fatty acids were purchased from TCI (Shanghai) Development Co., Ltd., as (A) Myristic acid (Cat.Num M0476; CAS number 544-63-8), (B) Palmitic acid (Cat.Num P0002; CAS number 57-10-3), (C) Stearic acid (Cat.Num S0163; CAS number 57-11-4), 
(D) cis-9-Hexadecenoic acid (Cat.Num H0072; CAS number 373-49-9) and (E) cis-9-Octadecenoic acid (Cat.Num O0011; CAS number 112-80-1).

\subsection{Sensory Evaluation}

The bitterness of each soup sample was estimated (averaged with three to four repetitions) by the quinine-sulfate (purchased from Sangon, Shanghai) equivalent test. The bitterness of a sample was compared with a series of quinine-sulfate dilutions using a sensory panel composed of ten trained students. The panelists were trained three times with standard quinine-sulfate solutions set at several concentrations [31] near the threshold levels. The panelists rinsed their mouths thoroughly with water and then keep $2 \mathrm{ml}$ soup in the mouth for $10 \mathrm{sec}$ before evaluation. The degree of bitterness was rated as not $(-)$, slightly $(+)$, distinctly $(++)$, moderately $(+++)$, very $(++++)$ and extremely bitter $(+++++)$. It is very important to locate the concentration(s) of the level 'extremely bitter $(+++++)$ ' for the standard, because any higher concentration than this level will produce the same sensory result and bring significant errors. They rated the bitterness intensity on the six-level scale while the sample was swished in the mouth. Participants then expectorated the sample and rinsed with filtered water as needed. An inter-stimulus interval of at least 2 min between samples was confirmed. The panel repeated the testing of the standard quinine-sulfate solutions set and adjusted the solution concentrations until all agreed with the rated results of bitterness. Each adjusted degree represented a quinine-sulfate concentration of $1.6,2.4,3.2,4.0,4.8$ and $5.6 \times 10^{-5} \mathrm{~mol} \mathrm{~L}^{-1}$, respectively [32]. Most kinds of the soups were then diluted in a way that their starting bitterness levels were not higher than (but as close as possible to) the level $(++++)$ so the de-bittering effects can be compared more accurately. For each test, the highest and lowest scores from the ten ones accessed by ten panel members were deleted and the left eight scores were practically averaged as the final score.

\section{Results}

\subsection{Cod and Salmon Bone Soups Had Little De-bittering Effects}

The potential de-bittering effects of cod and salmon soups were checked out in the beginning. First, Coptis chinensis, kuh-seng, bitter melon, cod bone and salmon bone were used to make respective soups as follow: $0.15 \mathrm{~g}$ Coptis chinensis $+330 \mathrm{ml}$ water, $0.75 \mathrm{~g}$ kuh-seng $+330 \mathrm{ml}$ water, $1.5 \mathrm{~g}$ bitter melon $+330 \mathrm{ml}$ water, $200 \mathrm{~g}$ cod bone $+350 \mathrm{ml}$ water, $200 \mathrm{~g}$ salmon bone $+350 \mathrm{ml}$ water, were well homogenated and mildly boiled for $20 \mathrm{~min}$ to get Coptis chinensis soup 300ml (a), kuh-seng soup 300ml (b), bitter melon soup $300 \mathrm{ml}$ (c), cod bone soup $300 \mathrm{ml}$ (d), and salmon bone soup $300 \mathrm{ml}$ (e), respectively. Second, $100 \mathrm{ml}$ bone soup (d or e) plus $100 \mathrm{ml}$ bitter substances ( $\mathrm{a}, \mathrm{b}$ or c) was further mildly boiled for $20 \mathrm{~min}$ and cooled down for 1 hour to room temperature before the sensory evaluation. The evaluation results were listed in Table 1, indicating that cod and salmon bone soups had no substantial de-bittering effects on the three typical bitter food or Chinese medicine.

Table 1. Cod and salmon bone soups had no de-bittering effects

\begin{tabular}{lllll}
\hline & $0 \mathrm{hr}$ & $1 \mathrm{hr}$ & $6 \mathrm{hr}$ & $20 \mathrm{hr}$ \\
\hline $\mathrm{a}$ & ++++ & ++++ & ++++ & ++++ \\
$\mathrm{b}$ & ++++ & ++++ & ++++ & ++++ \\
$\mathrm{c}$ & ++++ & ++++ & ++++ & ++++ \\
$\mathrm{d}+\mathrm{a}$ & ++++ & +++ & +++ & +++ \\
$\mathrm{d}+\mathrm{b}$ & ++++ & +++ & +++ & +++ \\
$\mathrm{d}+\mathrm{c}$ & ++++ & +++ & +++ & +++ \\
$\mathrm{e}+\mathrm{a}$ & ++++ & +++ & +++ & +++ \\
$\mathrm{e}+\mathrm{b}$ & ++++ & +++ & +++ & ++ \\
$\mathrm{e}+\mathrm{c}$ & ++++ & +++ & ++ & ++ \\
\hline
\end{tabular}

Note: a, b, c, d and e represent $300 \mathrm{ml}$ Coptis chinensis soup, $300 \mathrm{ml}$ kuhseng soup, $300 \mathrm{ml}$ bitter melon soup, $300 \mathrm{ml}$ cod bone soup, and $300 \mathrm{ml}$ salmon bone soup, respectively. The two soup combination $(200 \mathrm{ml})$ was made by $100 \mathrm{ml}$ bone soup ( $\mathrm{d}$ or e) plus $100 \mathrm{ml}$ bone soup ( $\mathrm{a}, \mathrm{b}$ or $\mathrm{c}$ ).

Actually, cod and salmon bone soups are not only unable to debitter, but they themselves, either alone or mixed, had slight bitterness (data not shown) which can be eliminated completely by the trout bone soup.

\subsection{De-bittering Effects of Trout Extract on Three Typical Bitter Soups}

Freshly made $100 \mathrm{ml}$ Coptis chinensis soup was mixed with $100 \mathrm{ml}$ trout bone soup plus $200 \mathrm{ml}$ water. After boiled for $20 \mathrm{~min}$ and stayed for 1 hour at the room temperature, the bitter taste of the Coptis chinensis soup was evaluated. It was found that the bitter taste was completely eliminated only after 1 hour treatment by the trout bone soup, with the evaluation score from $(++++)$ or $(+++++)$ to (-). The experiment repeated three times and got the similar results. Besides, the very similar results were obtained for kuh-seng and bitter mellon soups (Table 2).

Table 2. De-bittering effect of trout extract on three typical bitter soups

\begin{tabular}{lccc}
\hline & bitter melon soup $(\mathbf{5 m g} / \mathbf{m l})$ & kuh-seng soup $(2.5 \mathrm{mg} / \mathrm{ml})$ & coptis chinensis soup $(\mathbf{0 . 5 m g} / \mathbf{m l})$ \\
\hline \multirow{2}{*}{ Initial bitterness } & +++ & ++++ & ++++ \\
& ++++ & ++++ & + \\
Bitterness(1hr) & ++++ & - & - \\
& - & - & - \\
Bitterness (24hr) & - & - & - \\
& - & - & - \\
\hline
\end{tabular}




\subsection{Trout Bone Soup Composed of More Fat and Fatty Acids than Cod and Salmon Soups}

Both unsaturated and saturated fatty acids were found to have bitterness-masking effects or functions of modulating human taste responses [33-39]. But only saturated fatty acids were reported in some details for masking bitterness. In this study, the authors also performed saturated fatty acids composition analysis for three types of bone soups. The trout bone soup was found rich in both the general fat and fatty acids as shown in Table 3 (also in Table 1s), consistent with the eye observations on these soups. Among forty different fatty acids (Table 3), 19 kinds were not detected, and 7 kinds (myristic acid, palmitic acid, stearic acid, cis-9-hexadecenoic acid, cis-9-octadecenoic acid, cis-11-Eicosenoic acid and all cis-11,14,17-Eicosatrienoic acid) were all detected in all three soups. Especially, the concentrations of the 5 kinds of fatty acids in the trout bone soup were all significantly higher than cod and salmon soups, strongly suggesting that the combinations of the five kinds of fatty acids be responsible for the excellent bitterness-masking capacity.

\subsection{De-bittering Effects of Pure Fatty Acids on Three Typical Bitter Soups}

An $15 \mathrm{ml}$ sterile tube was used, to which was added 5 $\mathrm{ml}$ of $\mathrm{ddH}_{2} \mathrm{O}, 2.5 \mathrm{ml}$ of fresh Coptis chinensis soup, and $2.5 \mathrm{ml}$ of a fatty acid mixture (the combination of five fatty acids used were mixed according to Table 1 , the final molar concentration is the same as in the trout bone soup). After boiled for $20 \mathrm{~min}$ and stayed for 1hour at the room temperature, the bitter taste was evaluated. After 6 hours and 24 hours at room temperature, bitterness was evaluated again. According to the experimental control group, bitterness decreased from $(++++)$ to $(+$ or -$)$ as in Table 4. Similar results were observed for bitter melon soup (Supplementary Table 2s) and kuh-seng soup (Supplementary Table 3s).

Table 3. Fatty acid concentrations in three types of bone samples

\begin{tabular}{|c|c|c|c|c|}
\hline & \multirow{2}{*}{ Fatty acid } & \multicolumn{3}{|c|}{ Average concentration $\left(\mathrm{g} \mathrm{kg}^{-1}\right)$} \\
\hline & & $\operatorname{cod}$ & trout & salmon \\
\hline 1 & Heneicosanoic acid & ND & ND & ND \\
\hline 2 & Tricosanoic acid & ND & ND & ND \\
\hline 3 & trans-9-Octadecenoic acid & ND & ND & ND \\
\hline 4 & trans-trans-9,12-Octadecadienoic acid & ND & ND & ND \\
\hline 5 & Butyric acid & ND & ND & ND \\
\hline 6 & Caproic acid & ND & ND & ND \\
\hline 8 & Capric acid & ND & ND & ND \\
\hline 9 & Undecanoic acid & ND & ND & ND \\
\hline 10 & Lauric acid & ND & ND & ND \\
\hline 11 & Tridecanoic acid & ND & ND & ND \\
\hline 12 & Myristic acid & $0.0028(\alpha)$ & $0.064(\beta)$ & $0.017(\alpha)$ \\
\hline 13 & Pentadecanoic acid & ND & 0.0046 & ND \\
\hline 14 & Palmitic acid & $0.015(\alpha)$ & $0.254(\beta)$ & $0.034(\alpha)$ \\
\hline 15 & Margaric acid & ND & 0.0042 & ND \\
\hline 17 & Arachidic acid & ND & ND & ND \\
\hline 18 & Behenic acid & ND & ND & ND \\
\hline 19 & Lignoceric acid & ND & ND & ND \\
\hline 20 & cis-9-Tetradecenoic acid & ND & ND & ND \\
\hline 21 & cis-10-Pentadecenoic acid & ND & ND & ND \\
\hline 22 & cis-9-Hexadecenoic acid & $0.0022(\alpha)$ & $0.06(\beta)$ & $0.0142(\alpha)$ \\
\hline 23 & cis-10-Heptadecenoic acid & ND & ND & ND \\
\hline 24 & cis-11-Octadecenoic acid & ND & 0.05 & 0.0056 \\
\hline 25 & cis-9-Octadecenoic acid & $0.0146(\alpha)$ & $0.668(\beta)$ & $0.034(\alpha)$ \\
\hline 26 & cis-11-Eicosenoic acid & $0.0046(\alpha)$ & $0.007(\alpha)$ & $0.022(\alpha)$ \\
\hline 27 & cis-13-Docosenoic acid & ND & 0.0084 & 0.0084 \\
\hline 28 & cis-15-Tetracosenoic acid & ND & 0.0058 & 0.0022 \\
\hline 29 & all cis-9,12,15-Octadecatrienioc acid & ND & 0.0074 & ND \\
\hline 30 & all cis-11,14-Eicosadienoic acid & ND & 0.004 & ND \\
\hline 31 & all cis-11,14,17-Eicosatrienoic acid & $0.0015(\alpha)$ & $0.042(\alpha)$ & $0.024(\alpha)$ \\
\hline 34 & all cis-7,10,13,16,19-Docosapentaenoic acid & ND & 0.0068 & ND \\
\hline 35 & all cis-4,7,10,13,16,19-Docosahexaenoic acid & ND & 0.0032 & 0.0022 \\
\hline 36 & cis,cis-9,12-Octadecadienoic acid & ND & 0.062 & 0.0028 \\
\hline 37 & all cis-6,9,12-Octadecatrienioc acid & ND & 0.0062 & ND \\
\hline 38 & all cis-8,11,14-Eicosatrienoic acid & ND & 0.003 & ND \\
\hline 39 & all cis-5,8,11,14-Eicosateraenoic acid & ND & ND & ND \\
\hline 40 & all cis-13,16-Docosadienoic acid & ND & 0.0024 & ND \\
\hline 41 & Total fat & $0.06(\alpha)$ & $1.54(\beta)$ & $0.22(\gamma)$ \\
\hline
\end{tabular}

Note: Significant differences among the three groups in a row using Multiple comparisons (Tukey's test); Values with different letters ( $\alpha$, $\beta, \gamma$ ) in a row indicate that the average values are significantly different from each other $(\mathrm{P}<0.01)$; ND: not detected; The original data for the three replicates were provided in Supplementary Table 1s. 
Table 4. De-bittering effects of fatty acids on Coptis chinensis soup

\begin{tabular}{|c|c|c|c|c|c|c|c|c|c|c|c|c|c|c|c|}
\hline & $1 \mathrm{hr}$ & $6 \mathrm{hr}$ & $24 \mathrm{hr}$ & & $1 \mathrm{hr}$ & $6 \mathrm{hr}$ & $24 \mathrm{hr}$ & & $1 \mathrm{hr}$ & $6 \mathrm{hr}$ & $24 \mathrm{hr}$ & & $1 \mathrm{hr}$ & $6 \mathrm{hr}$ & $24 \mathrm{hr}$ \\
\hline $\mathbf{0}$ & ++++ & ++++ & ++++ & $\mathbf{A B}$ & ++- & + & + & $\mathrm{ABC}$ & ++ & ++ & +++ & ABCD & ++ & ++- & ++ \\
\hline $\mathbf{A}$ & ++ & +++ & ++- & $\mathbf{A C}$ & ++- & +- & +- & ABD & ++ & ++- & ++ & ABCE & ++- & ++- & ++- \\
\hline B & ++ & ++ & +++ & AD & +++ & ++ & ++ & $\mathbf{A B E}$ & ++- & ++ & ++ & ACDE & +++ & +++ & ++ \\
\hline C & +++ & ++- & ++- & $\mathbf{A E}$ & ++- & ++ & ++- & ACD & +- & ++- & ++- & ABDE & +++ & +++ & ++ \\
\hline D & ++- & ++- & +++ & BC & +++- & ++ & +++ & ACE & ++- & +++ & ++- & BCDE & +++ & ++- & +- \\
\hline \multirow[t]{5}{*}{$\mathbf{E}$} & +++ & ++- & +++ & BD & +++ & ++- & +++- & BCD & ++ & +++ & ++ & ABCDE & +- & +- & - \\
\hline & & & & BE & +++ & ++- & ++ & BCE & ++ & +++ & ++ & & & & \\
\hline & & & & CD & +++ & ++- & ++ & BDE & ++- & ++- & +++ & & & & \\
\hline & & & & CE & ++- & ++ & ++- & CDE & ++- & ++ & ++- & & & & \\
\hline & & & & DE & +++ & ++- & +++ & ADE & +++ & +++ & ++ & & & & \\
\hline
\end{tabular}

\section{Discussion}

The bitter taste of cod fish was previously studied using conventional methods [40] and the authors found that Flavourzyme ${ }^{\circledR}$ did not reduce the bitterness well while the use of butanol and cholestyramine resin separately or in combination reduced the bitter taste from fish protein hydrolysates to levels hardly discernible in $1 \%$ concentration. In this study, the bitter taste of cod fish bone soup was masked completely by trout bone soup, suggesting that the latter has some substance to interact with bitter taste receptors or scavenging bitter substances themselves. There are several types of naturally occurred substances that bind with bitter taste receptors, such as some lipoproteins, cyclodextrin and cyclofructan $[41,42,43]$. Among them, lipoproteins may be of a particular interest for this study because trout bone soup had a much higher lipid compositions as observed than other two kinds of bone soup, though the authors were still not sure whether lipoproteins [33] also play important roles for trout soup to mask bitter taste. Table 4 clearly indicated that the trout bone soup had higher concentrations of about 20 different fatty acids than cod and salmon soups. According to several reports, some fatty acids can be used to efficiently mask bitter taste $[34,35,36,44]$. Tomotake et al [34] and Fujita et al [35] found that fatty acid salts such as sodium stearate, palmitate, and laurate in relatively high concentrations of about $1 \%$ were able to reduce the bitter taste of a 100-ppm quinine solution significantly, while there was $2.54 \%$ palmitic acids in the trout soup (Table 4) and may contribute to mask the bitter taste. Ryousuke Homma et al [37] found that a $0.5 \mathrm{mM}$ mixture of palmitic acid, stearic acid and myristic acid significantly reduced the bitterness of quinine hydrochloride, while the concentration of the above mixture in the trout soup $(99 \mathrm{mM}, 21 \mathrm{mM}$ and $28 \mathrm{mM}$ for the three types of fatty acids respectively) was about 40 times larger than that of the above mixture used for the sensory test, which shall be adequate to demonstrate the bitterness-masking effects. The literature strongly supports that fatty acids interwine with bitterness-sensing signaling pathway $[38,39,45,46]$ and they did play an important role for trout soup to mask the bitter taste for both food and Chinese medicine.

It seems helpful to test whether concentrated cod or salmon bone soups can have similar de-bittering effect as trout bone soup in a dose-dependent manner. Because the concentrations of many fatty acids in the trout soup are 10-50 fold higher than the cod and salmon bone soups, it is not practical to concentrate cod and salmon bone soups to the similar fatty acid concentrations as in the trout bone soup. Actually, 5 and 10 fold concentrated cod and salmon bone soups had no comparable de-bittering effects as the trout bone soup (data not shown).

Many Chinese medicine soups are very bitter and hard for children to drink. Some direct and simple bitter-masking approaches in daily food and Chinese medicine are always of great need. In this study, a rainbow trout bone soup-based efficient de-bittering method was accidently discovered when the authors tried to attenuate the bitterness of the bone soups made from cod and salmon. Moreover, the total bitter taste of one typical food and two typical Chinese medicines was surprisingly removed simply by addition of the trout bone extract [47]. The strong de-bittering power of the trout bone soup was further confirmed by five pure fatty acids (myristic acid, palmitic acid, stearic acid, cis-9-hexadecenoic acid, and cis-9-octadecenoic acid) that had much higher concentrations in the trout soup than cod and salmon bone soups, though other combinations (less than five components) cannot achieve the same level of de-bittering effect. Potential molecular mechanisms under the five fatty acids combination are to be investigated in the future.

\section{Acknowledgements}

This study was supported by the following funds: NSFC (No.31071170); the Key research and development plan of Shandong Province (2016GSF115022); 2018 Weihai Scientific Innovation Project and the Natural Science Foundation of Shandong Province (ZR2018MC002).

\section{References}

[1] X.M. Gao (Beijing University of Chinese Medicine), Chinese Medicine, Press of Chinese Medicine in China, ISBN: 9787513240338. 2017.

[2] Y. Makita, et al., "Evaluation of the bitterness-masking effect of powdered roasted soybeans", Foods, 5. 44. June 2016.

[3] A.Dagan-Wiener, A. D. Pizio, I. Nissim, et al. "BitterDB: taste ligands and receptors database in 2019", Nucleic Acids Research, 8; 47(D1). D1179-D1185. January 2019.

[4] A. Dagan-Wiener, I. Nissim, N.B. Abu, et al., "Bitter or not? BitterPredict, a tool for predicting taste from chemical structure", Scientific Reports, 7. 12074. September 2017.

[5] L. Yang, Y. Bai, "Characteristics and the de-bittering methods of bitter peptides in protein hydrolysates", Guangzhou Food Science and Technology, 18. 22-25. February 2002.

[6] X.S. Zhou, "Study on Forming Mechanism and Control Methods of Bitter Taste from Protein Hydrolysates", Journal of Cereals \& Oils, 8. 20-24. August 2004. 
[7] M. Teruyoshi, H. Tadao, "Relationship between bitterness of peptides and their chemical structures", Agricultural and Biological Chemistry, 36. 1423-1431. January 1972.

[8] N. Ishibashi, Y. Arita, H. Kanehisa, et al., "Bitterness of leucine-containing peptides", Agricultural and Biological Chemistry, 51(9). 2389-2394. March 1987.

[9] M. Xie, H. Hou, S. Zhang et al., "Purification and identification of bitter peptides from codfish hydrolysate", Modern Food Science and Technology, 32. 190-195. February 2016.

[10] L.H. Klostermeyer, "Isolation and identification of a bitter peptide from Butterkaese cheese II", Milchwissenschaft-milk Science International, 29. 449-455. 1974.

[11] M.J. Cho, "Characterization of bitter peptides from soy protein hydmlysates", University of Missouri-Columbia. 2000.

[12] H. He, J. Wang, F. Pei et al., "Review on the relationship of structure to bitter taste of protein hydrolysate and de-bittering", Food Science, 27. 571-574. October 2006.

[13] Y.W. Wu and J. Ouyang, "Tasting functions of amino acids and peptides", China Condiment. 1, 21-24.2001.

[14] Pedersen B., "Removing bitterness from protein hydrolysates", Food Technology, 10. 96-98.1994.

[15] T. K. Murray, B.E. Baker, "Studies on protein hydrolysis. I. Preliminary observations and the taste of enzymic protein hydrolysates", Journal of the Science of Food and Agriculture, 3(10). 470-475. October 1952.

[16] K. Grohmann, J.A. Manthey, R.G. Cameron, B.S. Buslig, "Purification of citrus peel juice and molasses", Journal of Agricultural and Food Chemistry, 47(12). 4859-67. December 1999.

[17] G. O'Cuinn, R. FitzGerald, P. Bouchier, M. McDonnell, "Generation of non-bitter casein hydrolysates by using combinations of a proteinase and aminopeptidases", Biochemical Society Transactions, 27(4). 730-4. August 1999.

[18] M.J. Cho, N. Unklesbay, F.H. Hsieh and A.D. Clarke, "Hydrophobicity of bitter peptides from soy protein hydrolysates", Journal of Agricultural and Food Chemistry, 52(19). 5895-901. September 2004.

[19] G. Lalasidis, "Four new methods of De-bittering protein hydrolysates and a fraction of hydrolysates with high content of essential amino acids", Annales De La Nutrition Et De Lalimentation, 32. 709-723. February 1978.

[20] G.M. Roy, "The applications and future implications of bitterness reduction and inhibition in food products", Critical Reviews in Food Science and Nutrition, 29. 59-71. 1990.

[21] V.M. Sonawane, M. Saiffee, N.Y. Shinde, A.H. Hawaldar, "An update of taste masking methods and evaluation techniques", Der Pharmacia Lettre, 2. 1-15. January 2010.

[22] S. Joshi, H.U. Petereit, "Film coatings for taste masking and moisture protection", International Journal of Pharmaceutics, 457(2). 395-406. December 2013.

[23] S. L. Cantor, M. A. Khan, A. Gupta, "Development and optimization of taste-masked orally disintegrating tablets (ODTs) of clindamycin hydrochloride", Drug Development and Industrial Pharmacy, Early onlie 1-9, July 2014.

[24] Z. Aytac, T. Uyar, "Antioxidant activity and photostability of $\alpha$ tocopherol/ $\beta$-cyclodextrin inclusion complex encapsulated electrospun polycaprolactone nanofibers", European Polymer Journal, 79.140-149. June 2016.

[25] Yoshihisa Katsuragi \& Kenzo Kurihara, "Specific inhibitor for bitter taste", Nature, 365. 213-214, September 1993.

[26] W.S.U. Roland, R.J. Gouka, H. Gruppen, et al., “6Methoxyflavanones as bitter taste receptor blockers for hTAS2R39", PLoS One, 9(4). e94451. April 2014.

[27] E. Tokuyama, T. Shibasaki, H. Kawabe, et al., "Bitterness suppression of BCAA solutions by L-ornithine", Chemical \& Pharmaceutical Bulletin, 54(9). 1288-1292. September 2006.
[28] R. S. J. Keast and P. A. S. Breslin, "Bitterness suppression with zinc sulfate and Na-cyclamate: a model of combined peripheral and central neural approaches to flavor modification", Pharmaceutical Research, 22(11).1970-1977. November 2005.

[29] K. Gao, R. Yang, J. Zhang, et al., "Effects of Qijian mixture on type 2 diabetes assessed by metabonomics, gut microbiota and network pharmacology", Pharmacological Research, 130.93-109. April 2018.

[30] B. Joseph, D. Jini, "Antidiabetic effects of Momordica charantia (bitter melon) and its medicinal potency", Asian Pacific Journal of Tropical Disease, 3(2). 93-102. April 2013.

[31] R.S.J. Keast, J. Roper, "A complex relationship among chemical concentration, detection threshold, and suprathreshold intensity of bitter compounds", Chemical Senses, 32. 245-253. March 2007.

[32] K. Tenney, J. Hayes, S. Euston, R. Elias, and J. Coupland, "Binding of Caffeine and Quinine by Whey Protein and the Effect on Bitterness", Journal of Food Science, 82(2). 509-516. Feburary 2017.

[33] Y. Katsuragia, T. Yasumasua, K. Kuriharab, "Lipoprotein that selectively inhibits taste nerve responses to bitter substances", Brain Research,713. 240-245. March 1996.

[34] M. Tomotake, Y. Sugiura, T. Umeda and Y. Katsuragi, "Agent for reducing bitter taste for medicines and foods, etc. contains optionally unsaturated fatty acid/or their metal salts", Japan Patent, 10025253. 1998.

[35] H. Fujita and A. Kuroki, "Pharmaceutical formulations comprising sodium laurylsulfate as bitterness masking agent", EP, 1452177. 2004.

[36] T. Koriyama, S. Wongso, K. Watanabe and H. Abe, "Fatty acid compositions of oil species affect the 5 basic taste perceptions", Journal of Food Science, 67(2). 868-873. July 2006.

[37] R. Homma, H. Yamashita, J. Funaki, et al., "Identification of bitterness-masking compounds from cheese", Journal of Agricultural and Food Chemistry, 60. 4492-4499. May 2012.

[38] D. W. Pittman, C. E. Labban, A. A. Anderson, H. E. O'Connor, "Linoleic and oleic acids alter the licking responses to sweet, salt, sour, and bitter tastants in rats", Chemical Senses, 31. 835-843. November 2006.

[39] R. D. Mattes, "Effects of linoleic acid on sweet, sour, salty, and bitter taste thresholds and intensity ratings of adults", AJP Gastrointestinal and Liver Physiology, 292(5). G1243-8. June 2007.

[40] E. Dauksas, R. Slizyte, T. Rustad, I. Storro, "Bitterness in fish protein hydrolysates and methods for removal", Journal of Aquatic Food Product Technology, 13. 101-114. October 2008

[41] H. Mori, M. Nishioka and F. Nanjo, "Cyclodextrin and cyclofructan for inhibition of bitterness and astringency of foods and beverages", Japan Patent, 2006067895. 2006.

[42] A. Binello, G. Cravotto, G. M. Nano, P. Spagliardi, "Synthesis of chitosan-cyclodextrin adducts and evaluation of their bitter masking properties", Flavour and Fragrance Journal, 19(5). 394-400. September 2004.

[43] J. P. Ley, "Masking bitter taste by molecules", Chemosensory Perception, 1.58-77. March 2008.

[44] A. Pouru, P. Kuusisto, R. Lahtinen and L. Koponen, "Edible product with masked bitter, sour and /or astringent taste", I. WO Patent 2004093571A1. 2004.

[45] P. Masek, A. C. Keene, "Drosophila fatty acid taste signals through the PLC pathway in sugar-sensing neurons", PLoS Genetetics, 9(9). e1003710. September 2013.

[46] M. Takafumi, I. Kazuo, F. Tohru, "Why is fat so tasty? Chemical reception of fatty acid on the tongue", Journal of Nutritional Science and Vitaminology, 53. 1-4. January 2007.

[47] Z. Zhang, Y. Han, F. Jin and Y. Zhang, "A method to mask food bitterness by trout extraction", China Patent, No.201510970526.7. 2015. 


\section{Supplemental Information}

Table 1s. Original data of some fatty acid concentrations in three replicates of bone soup samples

\begin{tabular}{|c|c|c|c|c|c|c|c|c|c|c|c|c|c|}
\hline & & \multicolumn{4}{|c|}{$\operatorname{cod}$} & \multicolumn{4}{|c|}{ trout } & \multicolumn{4}{|c|}{ salmon } \\
\hline & & 1 & 2 & 3 & & 1 & 2 & 3 & & 1 & 2 & 3 & \\
\hline Myristic acid & A & 0.0028 & 0.0030 & 0.0023 & $\alpha$ & 0.064 & 0.061 & 0.070 & $\beta$ & 0.017 & 0.019 & 0.016 & $\alpha$ \\
\hline Palmitic acid & B & 0.015 & 0.019 & 0.0139 & $\alpha$ & 0.254 & 0.258 & 0.249 & $\beta$ & 0.034 & 0.031 & 0.039 & $\alpha$ \\
\hline Stearic acid & $\mathrm{C}$ & 0.0026 & 0.0031 & 0.0022 & $\alpha$ & 0.06 & 0.065 & 0.049 & $\beta$ & 0.0078 & 0.0082 & 0.0073 & $\alpha$ \\
\hline cis-9-Hexadecenoic acid & $\mathrm{D}$ & 0.0022 & 0.0025 & 0.0020 & $\alpha$ & 0.06 & 0.063 & 0.056 & $\beta$ & 0.0142 & 0.0152 & 0.0166 & $\alpha$ \\
\hline cis-9-Octadecenoic acid & E & 0.0146 & 0.0160 & 0.0138 & $\alpha$ & 0.668 & 0.675 & 0.661 & $\beta$ & 0.034 & 0.038 & 0.029 & $\alpha$ \\
\hline cis-11-Eicosenoic acid & & 0.0046 & 0.0050 & 0.0041 & $\alpha$ & 0.007 & 0.0074 & 0.0066 & $\alpha$ & 0.022 & 0.021 & 0.022 & $\alpha$ \\
\hline all cis-11,14, 17 -Eicosatrienoic acid & & 0.0015 & 0.0018 & 0.0012 & $\alpha$ & 0.042 & 0.041 & 0.046 & $\alpha$ & 0.024 & 0.027 & 0.019 & $\alpha$ \\
\hline Total fat & & 0.06 & 0.066 & 0.051 & $\alpha$ & 1.54 & 1.58 & 1.47 & $\beta$ & 0.22 & 0.24 & 0.21 & $\gamma$ \\
\hline
\end{tabular}

Note: Significant differences among the three groups in a row using Multiple comparisons (Tukey test); Values with different letters ( $\alpha, \beta, \gamma)$ in a row indicate that the average values are significantly different from each other $(\mathrm{P}<0.01)$;

Table 2s. De-bittering effects of fatty acids on bitter melon soup

\begin{tabular}{|c|c|c|c|c|c|c|c|c|c|c|c|c|c|c|c|}
\hline & $1 \mathrm{hr}$ & $6 \mathrm{hr}$ & $24 \mathrm{hr}$ & & $1 \mathrm{hr}$ & $6 \mathrm{hr}$ & $24 \mathrm{hr}$ & & $1 \mathrm{hr}$ & $6 \mathrm{hr}$ & $24 \mathrm{hr}$ & & $1 \mathrm{hr}$ & $6 \mathrm{hr}$ & $24 \mathrm{hr}$ \\
\hline $\mathbf{0}$ & ++++ & ++++ & ++++ & $\mathbf{A B}$ & ++- & ++ & +++ & $\mathbf{A B C}$ & + & ++ & +- & ABCD & +- & +- & + \\
\hline $\mathbf{A}$ & ++- & ++- & +++ & AC & ++ & ++ & ++- & ABD & ++ & ++ & +- & ABCE & ++ & +- & ++ \\
\hline B & ++ & ++- & ++- & AD & ++- & +++ & ++ & ABE & +++ & ++- & ++ & ACDE & ++- & ++ & +- \\
\hline C & ++ & ++ & ++ & $\mathbf{A E}$ & ++ & ++ & ++ & ACD & ++ & ++ & ++- & ABDE & ++ & +- & +- \\
\hline D & ++- & ++- & ++ & BC & +++ & ++- & ++- & $\mathrm{ACE}$ & ++- & ++ & ++ & BCDE & ++ & +- & ++ \\
\hline \multirow[t]{5}{*}{$\mathbf{E}$} & ++ & ++ & ++ & BD & ++- & ++- & +++ & BCD & +++ & ++- & ++- & ABCDE & - & + & + \\
\hline & & & & BE & +++ & +++ & +++ & BCE & ++ & +++ & ++ & & & & \\
\hline & & & & CD & ++ & ++- & ++ & BDE & ++- & +++ & ++ & & & & \\
\hline & & & & CE & ++- & ++- & ++- & CDE & ++- & ++- & +- & & & & \\
\hline & & & & DE & +++ & +++ & +++ & ADE & +++ & ++- & ++ & & & & \\
\hline
\end{tabular}

Table 3s. De-bittering effects of fatty acids on kuh-seng soup

\begin{tabular}{|c|c|c|c|c|c|c|c|c|c|c|c|c|c|c|c|}
\hline & $1 \mathrm{hr}$ & 6hr & $24 \mathrm{hr}$ & & $1 \mathrm{hr}$ & 6hr & $24 \mathrm{hr}$ & & $1 \mathrm{hr}$ & 6hr & $24 \mathrm{hr}$ & & $1 \mathrm{hr}$ & 6hr & $24 \mathrm{hr}$ \\
\hline $\mathbf{0}$ & ++++ & ++++ & +++- & $\mathbf{A B}$ & ++ & ++ & ++- & $\mathbf{A B C}$ & + & ++ & +++ & ABCD & +- & +- & ++ \\
\hline $\mathbf{A}$ & ++- & ++ & +- & AC & +- & ++- & +++ & ABD & ++ & ++ & +++ & ABCE & ++ & ++ & ++ \\
\hline B & ++- & ++ & ++ & AD & ++ & ++ & ++- & $\mathbf{A B E}$ & +++ & ++ & +++ & ACDE & ++- & +- & ++ \\
\hline C & ++- & ++- & +++ & $\mathbf{A E}$ & +- & ++ & ++- & ACD & ++ & ++- & +++ & ABDE & ++ & +- & ++ \\
\hline D & +- & ++ & ++- & BC & +++ & ++- & ++ & ACE & ++- & ++ & +++- & BCDE & ++ & ++ & ++ \\
\hline \multirow[t]{5}{*}{$\mathbf{E}$} & ++ & ++- & ++- & BD & ++ & ++ & ++ & BCD & +++ & ++ & +++- & ABCDE & - & + & +- \\
\hline & & & & BE & ++- & ++- & +- & BCE & ++ & ++- & +++ & & & & \\
\hline & & & & CD & +- & ++ & ++ & BDE & ++ & ++- & ++- & & & & \\
\hline & & & & CE & +- & ++ & +- & CDE & ++- & +++ & ++ & & & & \\
\hline & & & & DE & ++ & ++- & +++ & ADE & +++ & ++ & +++ & & & & \\
\hline
\end{tabular}

(C) The Author(s) 2019. This article is an open access article distributed under the terms and conditions of the Creative Commons Attribution (CC BY) license (http://creativecommons.org/licenses/by/4.0/). 